\title{
Stabilization Effect of Resin on the Production of Potent Proteasome Inhibitor NPI-0052 During Submerged Fermentation of Salinispora tropica
}

\author{
Ginger Tsueng, Kin S. Lam
}

Received: March 30, 2007 / Accepted: July 14, 2007

(C) Japan Antibiotics Research Association

\begin{abstract}
Addition of acrylic resin Amberlite XAD-7 during the fermentation of Salinispora tropica significantly enhanced the production of NPI-0052 by 69 fold. Examination of the time course of resin addition to the Salinispora tropica fermentation demonstrated that the increase in the production of NPI-052 is due to the stabilization effect by resin but not the removal of an end product feedback repression. Delay in resin addition to the fermentation led to decreases in the production of NPI0052 to the amounts that are synthesized prior to the resin addition.
\end{abstract}

Keywords NPI-0052, proteasome inhibitor, Salinispora tropica, Amberlite XAD-7 resin

NPI-0052 (salinosporamide A) is a novel, potent proteasome inhibitor [1 3] isolated from the marine obligate actinomycete Salinispora tropica [4]. It possesses a broad spectrum of activities against various tumors in animal models $[1,2,5]$. It is currently undergoing Phase I clinical studies for the treatment of patients with various cancers [2]. Structural studies revealed that NPI-0052 comprises a fused $\gamma$-lactam- $\beta$-lactone ring system that is decorated with a cyclohexenyl carbinol at the C-4 ring junction, a chloroethyl substituent at C-2, and a methyl group at the C-3 ring junction (Fig. 1) [4]. Structure-

K. S. Lam (Corresponding author), G. Tsueng: Nereus Pharmaceuticals, Inc., 10480 Wateridge Circle, San Diego, CA 92121, USA, E-mail: rlam@nereuspharm.com activity relationship and mechanistic studies indicated that the $\beta$-lactone ring system and the chlorine atom are required for the potent activity of NPI-0052 [3, 6]. The $\beta$-lactone ring system is susceptible to hydrolysis in an aqueous environment [6, 7], such as the submerged fermentation condition for the production of NPI-0052 by $S$. tropica. End product feedback repression of secondary metabolite biosynthesis is a well known phenomenon [8]. The extremely potent activity of NPI-0052 may lead to end product repression of its biosynthesis, which would limit the biosynthesis of NPI-0052 by S. tropica. These factors may be responsible for the initial low production of NPI0052 , about $4.0 \mathrm{mg} /$ liter, in the submerged fermentation of

\section{S. tropica.}

It has been well documented that the addition of resins to the fermentations of reactive and/or highly potent secondary metabolites led to increases in production of these metabolites [9 12]. Therefore, we examined the effect of Amberlite XAD-7 resin on the production of NPI0052 by $S$. tropica. This communication describes the

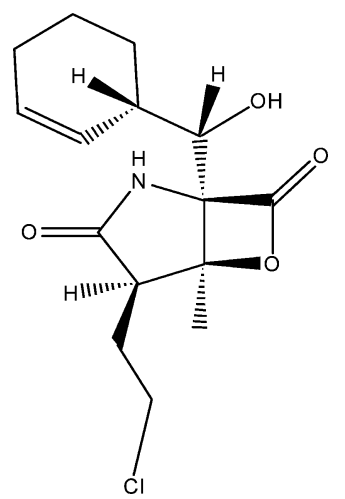

Fig. 1 Structure of NPI-0052. 
increase in the titer of NPI-0052 produced by S. tropica as a result of resin addition.

\section{Materials and Methods}

\section{Microorganism}

The producing strain, S. tropica NPS21184 was deposited with the American Type Culture Collection and assigned the accession number PTA-6685.

\section{Growth Media and Culturing Conditions}

The growth media and culturing conditions have been described previously [13] with the modification of resin addition schedule.

\section{Growth Analysis, Extraction and Analytical Methods}

The growth analysis by packed cell volume, the preparation of fermentation extract for HPLC analysis and the HPLC conditions for monitoring the production of NPI-0052 have been described previously [13]. The growth of culture was expressed as \% packed cell volume defined as volume of packed cell/volume of culture $\times 100 \%$.

\section{Results and Discussion}

\section{Production of NPI-0052 at Different Times of Resin Addition}

Denora et al. [7] demonstrated that NPI-0052 is rapidly degraded in the aqueous environment such as phosphate buffer $(0.05 \mathrm{M})$ at $\mathrm{pH} 6.5$ and $25^{\circ} \mathrm{C}$ with a $t_{50 \%} \sim 140$ minutes. This may explain the low titer of NPI-0052 observed in the submerged fermentation of $S$. tropica. Preliminary study was carried out to determine the effect of resins in enhancing the production of NPI-0052 by adding Amberlite XAD-4, Amberlite XAD-7 and Amberlite XAD-
16 resin to the shake flask cultures at 24 hours at a final concentration of $20 \mathrm{~g} /$ liter. It was determined that Amberlite XAD-7 was the most effective resin tested in increasing the production of NPI-0052 (Table 1). It was also determined that increasing the concentration of Amberlite XAD-7 in the fermentation to $30 \mathrm{~g} /$ liter did not improve the production of NPI-0052, indicating that the final concentration of resin at $20 \mathrm{~g} /$ liter was optimal for the current production of NPI-0052 in shake flask culture. Amberlite XAD-7 resin was selected for the time course study. Table 2 shows the production of NPI-0052 in shake flask cultures with the acrylic Amberlite XAD-7 resin (20 g/liter final concentration) added at 24, 48, 72 or 96 hours, and the control culture with no resin addition. In the control culture, the production of NPI-0052 was first observed at 48 hours. The peak production of $4.0 \mathrm{mg} / \mathrm{liter}$ was observed at 72 hours in the control culture and continued to drop to $2.0 \mathrm{mg} /$ liter and $0.1 \mathrm{mg} /$ liter at 96 hours and 120 hours, respectively. When resin was added to the culture at 24 hours, we observed a significant increase in the production of NPI-0052, with the peak titer of $275 \mathrm{mg} /$ liter detected at 96 hours. This corresponds to a 69fold increase in the production of NPI-0052 as compared to the control culture. This observation is similar to the yield improvement by resin on production of the highly reactive and the most potent antitumor agents esperamicin and

Table 1 Effect of Amberlite XAD-4, Amberlite XAD-7 and Amberlite XAD-16 resin on the production of NPI-0052 in shake flask cultures of Salinispora tropica

\begin{tabular}{lc}
\hline \multicolumn{1}{c}{ Resin } & NPI-0052 (mg/liter) \\
\hline No addition & 5.7 \\
Amberlite XAD-4 (20 g/liter) & 207 \\
Amberlite XAD-7 (20 g/liter) & 278 \\
Amberlite XAD-16 (20 g/liter) & 218 \\
\hline
\end{tabular}

Table 2 Time course of NPI-0052 production in shake flask cultures of Salinispora tropica with different times of Amberlite XAD-7 resin addition

NPI-0052 (mg/liter)

\begin{tabular}{lccrrrr} 
Time of resin addition & 24 hours & 48 hours & 72 hours & 96 hours & 120 hours & 144 hours \\
\cline { 2 - 6 } & 0 & 3 & 4 & 2 & 0.1 & 245 \\
No addition & 0 & 62 & 233 & 275 & 222 & 1 \\
24 hours & ND & 3 & 158 & 224 & 99 & 92 \\
48 hours & ND & ND & 4 & 108 & 15 \\
72 hours & ND & ND & ND & 2 & 10 \\
\hline 6
\end{tabular}

$\mathrm{ND}=$ Not determined 
Table 3 Correlation of titer of NPI-0052 in shake flask cultures of Salinispora tropica with different times of Amberlite XAD-7 resin addition

\begin{tabular}{lccc}
\hline Time of resin addition & $\begin{array}{c}\text { Difference in titer as } \\
\text { compared to 24 hours } \\
\text { resin addition (mg/liter) }\end{array}$ & $\begin{array}{c}\text { Amount of NPI-0052 synthesized } \\
\text { since resin addition at } \\
24 \text { hours (mg/liter) }\end{array}$ \\
\hline 24 hours & 275 & - & - \\
48 hours & 224 & 51 & 62 \\
72 hours & 108 & 167 & 158 \\
\hline
\end{tabular}

dynemicin of the enediyne class $[9,10]$. In that system, the resin showed both stabilization and removal of feedback repression of esperamicin and dynemicin biosynthesis. Based on the improvement in yield shown for Amberlite XAD-7 with NPI-0052, and since this molecule is a highly reactive and extremely potent antitumor agent, one might hypothesize that this resin showed both stabilization and removal of feedback repression effects on the production of NPI-0052 also.

\section{Mechanism of the Effect of Resin on the Production of NPI-0052}

In order to elucidate the mechanism of the effect of resin on the production of NPI-0052, we compared the production of NPI-0052 with different times of resin addition to the culture. When resin was added to the cultures later than 24 hours, the peak production of NPI-0052 was decreased. The later the time of resin addition, the lower the peak titers of NPI-0052. The peak titer of 275, 224, 108 and $15 \mathrm{mg} /$ liter were detected at 24, 48, 72 and 96 hours resin addition, respectively (Table 2 ). The drop in the production of NPI-0052 when the resin was added later than 24 hours can be accounted for by the loss of NPI-0052 synthesized during the period by degradation (hydrolysis) in the absence of resin (Table 3). From 24 to 48 hours, the culture was capable of producing $62 \mathrm{mg} /$ liter of NPI-0052, which can be accounted for by the drop in titer of $51 \mathrm{mg} /$ liter when resin was added to the culture at 48 hours instead of 24 hours (Table 3). By the same token, the drop in titer of $167 \mathrm{mg} /$ liter at 72 hours resin addition as compared to 24 hours resin addition was due to the loss of the synthesis of $158 \mathrm{mg} /$ liter by degradation during the 48 hours period (i.e., from 24 to 72 hours) (Table 3 ). The above observation clearly demonstrated that the increase in the production of NPI-0052 is due to the stabilization effect by resin but not by removal of end product feedback repression. The presence of 3 to $4 \mathrm{mg} /$ liter unbound NPI-0052 in the culture did not exert any adverse effect on further production of NPI-0052.

\section{Effect of Resin Addition on the Growth Yield and $\mathrm{pH}$ of the Fermentation}

Different time of resin addition to the shake flask culture did not affect the growth of the organism and the $\mathrm{pH}$ of the fermentation. The growth yield and the $\mathrm{pH}$ were essentially the same throughout the fermentation in the control culture and the cultures with different times of resin addition. At 96 hours (peak NPI-0052 production), all cultures have the same packed cell volume $(6.0 \%)$ and the same $\mathrm{pH}$ range of 7.3 to 7.4 .

\section{Conclusion}

We established that the optimal time of resin addition to the shake flask culture for NPI-0052 production is 24 hours of the production cycle. Resin acted as the "stabilization agent" by binding to NPI-0052 to minimize the hydrolytic effect of the aqueous environment during the submerged fermentation of $S$. tropica and increased the production of NPI-0052 by 69 -fold.

\section{References}

1. Chauhan D, Catley L, Li G, Podar K, Hideshima T, Velankar M, Mitsiades C, Mitsiades N, Yasui H, Letai A, Ovaa H, Berkers C, Nicholson B, Chao TH, Neuteboom STC, Richardson P, Palladino MA, Anderson KC. A novel orally active proteasome inhibitor induces apoptosis in multiple myeloma cells with mechanisms distinct from Bortezomib. Cancer Cell 8: 407-419 (2005)

2. Chauhan D, Hideshima T, Anderson KC. A novel proteasome inhibitor NPI-0052 as an anticancer therapy. Brit J Cancer 95: 961-965 (2006)

3. Groll M, Huber R, Potts BCM. Crystal structures of salinosporamide A (NPI-0052) and B (NPI-0047) in complex with the $20 \mathrm{~S}$ proteasome reveal important consequences of beta-lactone opening and a mechanism for irreversible binding. J Am Chem Soc 128: 5136-5141 (2006)

4. Feling RH, Buchanan GO, Mincer TJ, Kaufman CA, Jensen PR, Fenical W. Salinosporamide A: a highly cytotoxic 
proteasome inhibitor from a novel microbial source, a marine bacterium of the new genus Salinispora. Chem Int Ed 42: 355-357 (2003)

5. Cusack JC, Liu R, Xia L, Chao T-H, Pien C, Niu W, Palombella VJ, Neuteboom STC, Palladino MA. NPI-0052 enhances tumoricidal response to conventional cancer therapy in a colon cancer model. Clin Cancer Res 12: 6758-6764 (2006)

6. Macherla VR, Mitchell SS, Manam RR, Reed KA, Chao T, Nicholson B, Deyanat-Yazdi G, Mai B, Jensen PR, Fenical WF, Neuteboom STC, Lam KS, Palladino MA, Potts BCM. Structure-activity relationship studies of NPI-0052, a novel marine derived 20S proteasome inhibitor. J Med Chem 48: 3684-3687 (2005)

7. Denora N, Potts BCM, Stella VJ. A mechanistic and kinetic study of the $\beta$-lactone hydrolysis of salinosporamide A (NPI-0052), a novel proteasome inhibitor. J Pharm Sci 96: 2037-2047 (2007)

8. Martin JF, Demain AL. Control of antibiotic biosynthesis. Microbiol Rev 44: 230-251 (1980)
9. Lam KS, Gustavson DR, Veitch JA, Forenza S. Effect of cerulenin on the production of esperamicin $A_{1}$ by Actinomadura verrucosospora. J Ind Microbiol 12: 99-102 (1993)

10. Lam KS, Veitch JA, Lowe SE, Forenza S. Effect of neutral resins on the production of dynemicins by Micromonospora chersina. J Ind Microbiol 15: 453-456 (1995)

11. Woo EJ, Starks CM, Carney JR, Arslanian R, Cadapan L, Zavala S, Licari P. Migrastatin and a new compound, isomigrastatin, from Streptomyces platensis. J Antibiot 55: 141-146 (2002)

12. Frykman S, Tsuruta H, Galazzo J, Licari P. Characterization of product capture resin during microbial cultivations. J Ind Microbiol Biotechnol 33: 445-453 (2006)

13. Reed KA, Manam RR, Mitchell SS, Xu J, Teisan S, Chao TH, Deyanat-Yazdi G, Neuteboom STC, Lam KS, Potts BCM. New salinosporamides from the marine actinomycete Salinispora tropica and thioester derivatives, potent inhibitors of 20S proteasome. J Nat Prod 70: 269-276 (2007) 